Check for updates

Cite this: J. Mater. Chem. B, 2017, 5,5714

Received 7th May 2017, Accepted 4th July 2017

DOI: $10.1039 / \mathrm{c} 7 \mathrm{tb} 01241 \mathrm{a}$

rsc.li/materials-b

\section{Contrast agents for cardiovascular magnetic resonance imaging: an overview}

\author{
Marco M. Meloni, ${ }^{\mathrm{ab}}$ Stephen Barton, (D) ${ }^{\mathrm{b}}$ Lei $\mathrm{Xu},{ }^{\mathrm{c}}$ Juan C. Kaski, ${ }^{a}$ Wenhui Song ${ }^{\mathrm{d}}$ \\ and Taigang $\mathrm{He}^{\star \mathrm{ae}}$
}

Cardiovascular Magnetic Resonance (CMR), a non-invasive and nonionizing imaging technique, plays a major role in research and clinical cardiology. The strength of CMR lies in its high temporal resolution, superior contrast, and unique tissue characterization capabilities. Contrast agents have been used to improve sensitivity and specificity of CMR in detecting and evaluating various pathologies. Much effort has been made to develop more efficient contrast reagents to detect cardiovascular diseases at an asymptomatic stage, which has led to a plethora of products in animal studies. However, very few of the developed contrast agents are currently approved for human use. Major obstacles are high dosages, toxicity, body clearance rate and long-term immunogenicity. In this review, we critically assess recent developments in the field of the contrast agents for CMR, highlighting both benefits and current drawbacks. A clearer insight regarding the challenges facing the development of improved contrast agents may help collaborative work to enhance images contrast, decrease toxicity and accelerate their translation into clinical use.
${ }^{a}$ Molecular and Clinical Sciences Research Institute, St George's,

University of London, London, UK. E-mail: mmeloni@sgul.ac.uk, the@sgul.ac.uk

${ }^{b}$ School of Pharmacy and Chemistry, Kingston University, London, UK

${ }^{c}$ Department of Radiology, Beijing Anzhen Hospital, Beijing, China

${ }^{d}$ UCL Centre for Biomaterials, Division of surgery \& Interventional Science,

University College of London, London, UK

${ }^{e}$ Royal Brompton Hospital, Imperial College London, London, UK

\section{Introduction}

Cardiovascular diseases (CVDs) are a group of disorders of the heart and blood vessels and remain the biggest cause of deaths worldwide, representing $31 \%$ of all deaths. ${ }^{1}$ Cardiovascular imaging plays a pivotal role in modern health care and constitutes an essential component in the management of patients with cardiovascular conditions. Current imaging modalities for

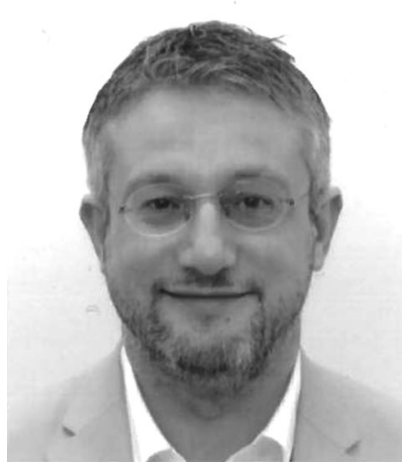

Marco M. Meloni
Dr Marco M. Meloni graduated in Italy at the University of Sassari under the supervision of Professor M. Taddei. He gained his PhD at Southampton University with Professor R. C. D. Brown, developing a novel class of silicon linkers for solid phase organic synthesis. He was then a PDRA at Manchester and Sheffield Universities working with Professors S. Faulkner, S. Flitsch and S. Jones, developing targeted contrast reagents for Molecular Imaging and glycobiology. He currently holds a BHF fellowship at St George's University of London and honorary fellowships at Kingston University and UCL, under the supervision of Drs T. He, $S$. Barton and W. Song, developing novel contrast reagents for molecular imaging of cardiovascular diseases.

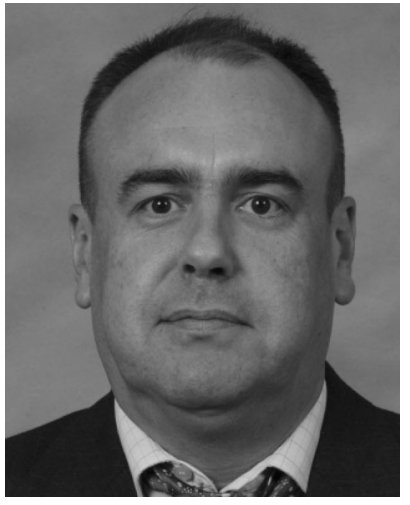

Stephen Barton
Dr Stephen Barton CSci, CChem, MRSC is Associate Professor in Pharmaceutical Analysis at Kingston University, UK. His first degree is in chemistry and he gained a PhD in the diffusion characteristics and electrical properties of novel thermosetting resins from Kingston University. His current research interests include synthesis and properties of conducting polymer blends and analysis of pharmaceutical degradation studies using NMR and $L C-M S$. 
assessment of CVDs include ultrasonography, Positron Emission Tomography (PET), Computed Tomography (CT) and Magnetic Resonance Imaging (MRI). Since the pioneering work of Lauterbur and Mansfield in the $1970 \mathrm{~s},{ }^{2}$ MRI has become a staple of imaging modality in medical science and clinical practice. For the heart and vascular system, the term CMR is often used. To note, although it is often routinely used for CVS imaging, CT is an X-ray based modality known for its radiation problems. By contrast, CMR does not use radiation and has no known side effects. CMR also affords superb soft tissue contrast, providing a comprehensive assessment of cardiac morphology, function, perfusion, viability, coronary artery stenosis and quantitative tissue characterisation. ${ }^{3}$ In view of these capabilities, CMR is often known as the "one-stop shop" for virtually any form of cardiovascular disease.

Because the endogenous differences between tissues in MRI can be small, a contrast agent (CA) is often used in MRI to provide additional contrast to distinguish a target tissue from its surroundings. In 1988, the first CA specifically designed for MRI, a complex of gadolinium ion $\left(\mathrm{Gd}^{3+}\right)$ and 1,4,7,10-tetraazacyclododecane-1,4,7,10 carboxylic acid (Gd-DOTA), became available

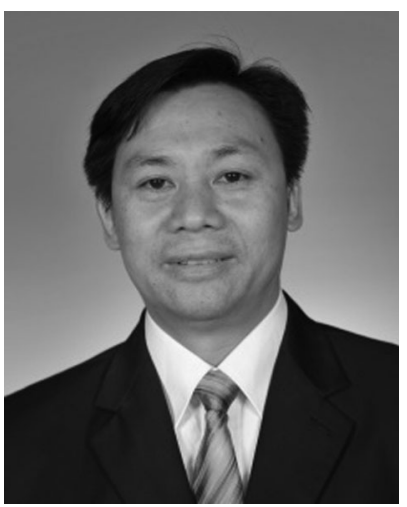

Lei Xu
Professor of Radiology, Department of Radiology, Beijing Anzhen Hospital, Capital Medical University, China. He gained his $M D$ and $P h D$ degrees in diagnostic radiology from Capital Medical University in China. His research interests focus on cardiovascular CT and cardiovascular MRI.

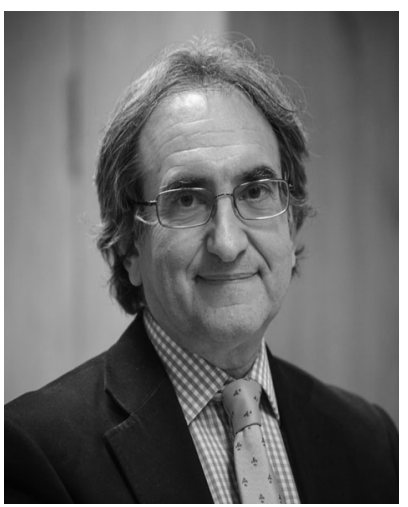

Juan C. Kaski
J. C. Kaski, DSc, MD, DM (Hons), FRCP, FESC, FACC, FAHA, is Professor of Cardiovascular Science at St George's, University of London (SGUL), Honorary Consultant Cardiologist at St George's Hospital, London, UK, Immediate Past Director of the Cardiovascular and Cell Sciences Research Institute at SGUL and Past-President of ISCP. Prof. Kaski is Doctor of Science (University of London), Gold Medallist (Spanish Society of Cardiology and Fukushima University in Japan) and Doctor Honoris Causa of several universities worldwide. Professor Kaski is editorial board member of JACC and the European Heart Journal among 20 other peer review journals. He is Editor-in-Chief of European Cardiology Review Journal and the ISCP Pharmacotherapy series and Deputy Editor, International Journal of Cardiology. Prof. Kaski has published over 450 papers in peer-review journals, over 300 invited papers and book chapters and edited six books.

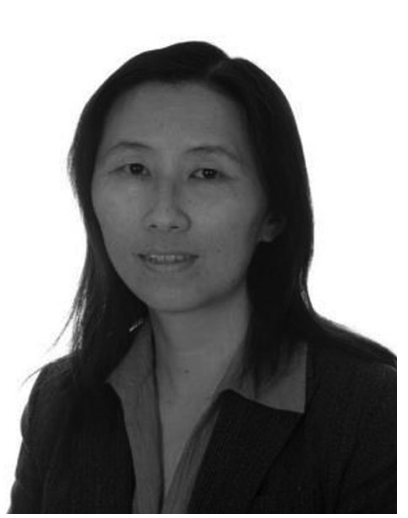

Wenhui Song
Wenhui Song received her PhD from the University of Cambridge in $\mathrm{UK}$, BEng and MEng from Beihang University in China. She is currently Reader and Director of the Centre for Biomaterials in the Division of Surgery and Interventional Science, University College London. Her research is primarily focused on three main areas: polymeric biomaterials, nanomaterials and nanocomposites for drug delivery and regenerative medicines, scaffolds for tissue regeneration and artificial organs, and implantable sensors and devices. Her laboratory is also developing novel bio-manufacturing technologies, such as engineered self-assembling, 3D bioprinting, and electrospinning for production of nanomedicines, scaffolds, implants, sensors and devices.

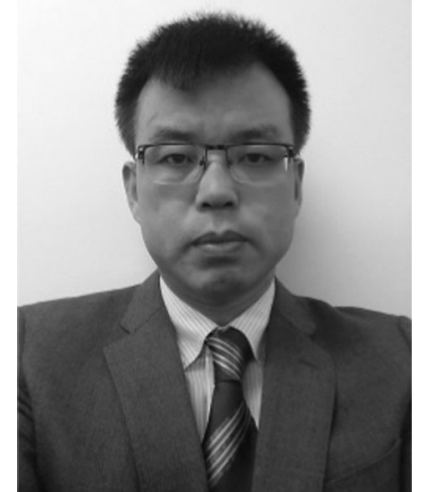

Taigang He
Dr Taigang He is currently a senior lecturer of cardiovascular imaging at St George's, University of London. He also holds an honorary position at Imperial College London. He aims to help clinicians increase detection rates, reduce healthcare costs, and most importantly save lives by using novel imaging techniques and emerging big data analytics. His research interests include cardiovascular magnetic resonance, myocardial tissue characterization, medical image computing, and artificial intelligence in biomedical and health Informatics. 
for clinical use. ${ }^{4}$ Since then, many and varied CAs have been developed to increase the sensitivity and specificity of detecting and evaluating various pathologies. In CMR, CAs have played a key role in a variety of applications such as perfusion, ${ }^{5}$ viability, ${ }^{6}$ tissue characterisation, ${ }^{7}$ angiography ${ }^{8-10}$ and more recently molecular imaging studies. ${ }^{11}$ Today, the CAs development continues to evolve, bringing exciting opportunities for more sensitive and targeted imaging to improve patient outcome, along with associated challenges.

Many CAs developed are however limited to proof-of-concept preclinical studies, and very few of them are currently approved for human use. In our opinion, the major obstacles include high dosages, toxicity, body clearance rate and long-term immunogenicity. In this review, instead of a detailed description of its history and clinical applications, we aim at critically assessing recent developments of CA in the field of CMR, highlighting both benefits and drawbacks. An insight into challenges facing the CAs' development may promote coordinated effort in producing improved CMR agents and accelerating translation of the development into clinical use.

\section{Basics of tissue contrast in CMR}

CMR scanners use strong magnetic fields, radiofrequency waves, and field gradients to generate images of the heart. The radiofrequency emission is tissue dependent which give rise to the unparalleled ability of CMR to distinguish subtle differences in the cardiovascular system. Briefly speaking, natural or intrinsic tissue contrast is due to difference in the measured signals which are majorly determined by four parameters in CMR: proton density, $T_{1}, T_{2}$, and flow. Proton density presents its concentration in tissue in the form of water and macromolecules (proteins, fat, etc.). The $T_{1}$ and $T_{2}$ relaxation define the way that the excited protons revert back to their equilibrium states. The effect of flow may be complex but the most common one is loss of signal from rapidly flowing blood. CMR can produce tailored contrast for a certain pathological condition by optimising these parameters in a pulse sequence. We herein refer to Manning and Pennell's monograph $^{12}$ for physics principles and a comprehensive description of CMR.

Even though CMR has a high contrast sensitivity relative to most other imaging modalities, the intrinsic tissue characteristics can overlap for example between normal, reversibly and irreversibly damaged heart. In this scenario, CAs can be used to enhance the intrinsic characteristics within specific tissues or region of interest.

CAs for CMR can be classified according to various features like the presence of a metal ion centre (usually $\mathrm{Gd}^{3+}$ ), the ability to alter preferentially $T_{1}$ or $T_{2}$, their affinity for CVS, their effect on image, or their chemical structures. As these features are intimately related, a unique classification is unlikely.

The affinity of a CA for CVS is probably the most known property by the scientific community. We will use this feature to differentiate CAs between conventional and molecular. Conventional CAs are untargeted and passively absorbed in the damaged areas of CVS whilst molecular CAs target specific biomolecules expressed in the CVS during disease development.
Given the growing interest in CVDs at a molecular level, the field of molecular CAs is rapidly emerging. The synergistic combination of CMR and molecular imaging is expected to provide a much better contrast of diseased CVS, providing invaluable information on atherogenesis processes. Albeit on its infancy, research in this field has been enormous and already led to a plethora of targeted $T_{1}$ and $T_{2}$-based contrast reagents.

\section{Developing efficient contrast agents: challenges and key factors}

\subsection{The balance between dosage and side effects}

Generally speaking, a good CA needs to afford higher contrast of diseased CVS, but with a dosage at which virtually no short and long-term toxicity are encountered. Current CA dosage for CMR can be up to $0.3 \mathrm{mmol} \mathrm{kg}^{-1} \mathrm{M}^{13,14}$ Dosages over $0.3 \mathrm{mmol}$ $\mathrm{kg}^{-1}$ may provide a further improvement, however, there is a great concern over increased toxicity. Serious acute and chronic effects have been reported even at clinically approved dosage, and a notorious example is the so-called Nephrogenic Systemic Fibrosis (NSF). ${ }^{15,16}$ Additionally, a recent concern is the possible adverse effect of Gd accumulation in patients' brains. ${ }^{17-19}$ The clinical significance of this remains unclear, nevertheless in the absence of sufficient evidence, the lowest possible dosage of Gd-based CAs is highly recommended.

\subsection{The chemical challenge}

From a chemist's perspective, the synthesis of more efficient CAs faces a great challenge: it must be simple, reliable, time saving, high yielding, and scalable at least to kilogram scale. Given the growing need of CAs for CMR, this challenge will become more and more prominent in the future.

The recent merging molecular CMR also leads to the development of the so-called targeted CAs. Compared to conventional CAs, these agents are more specific by binding key biomolecules expressed during CVDs to generate a better contrast. However, synthesis of these agents is usually laborious and time consuming, and low yields are usually encountered requiring novel protocols and optimization. If such challenges are addressed, molecular CMR can be implemented in a cost and time-effective fashion, representing a significant contribution alongside traditional CMR.

\subsection{Key factors}

When facing the aforementioned challenges, the researcher must consider several key properties of a promising CA: its ability to alter $T_{1}$ and $T_{2}$, body retention and clearance, side effects and the capability to accumulate preferentially in damaged CVS. A typical example is Late Gadolinium Enhancement (LGE), a well-known CMR protocol, ${ }^{20}$ which illustrates the importance of these factors. LGE heavily relies on a passive accumulation of the CA in damaged CVS, therefore a contrast medium with slow body clearance will have a great impact in lowering the dose, minimising side effects and addressing the challenges mentioned in the previous sections. ${ }^{21}$ 


\subsection{The impact of molecular structure}

The chemical structure of a CA is fundamental for understanding its mode of action. By using the current CAs as a lead and the Structure-Activity Relationship (SAR), synthetic and medicinal chemists can predict and design improved CAs by tuning their capability to alter $T_{1}$ and $T_{2}$, increase their stability ${ }^{22}$ in the bloodstream and improve specificity for damaged CVS. Chemists can also design novel synthetic routes of promising CAs in a costeffective fashion. A clear example of SAR importance emerged in the 1980s with the advent of the first generation of Gd-based CAs, which will be described more in details in Section 4.1.1.

\section{Conventional contrast reagents for CMR}

Conventional CAs can alter preferentially $T_{1}$ or $T_{2}$ and will be described respectively in Sections 4.1 and 4.2. To note, CAs alter both $T_{1}$ and $T_{2}$ of the water protons; however, such effects are usually more pronounced for either $T_{1}$ or $T_{2}$, and it is their relative ratio that influence the categorization as either $T_{1}$ or $T_{2}$ based CAs.

\section{1 $T_{1}$-Based contrast agents: general remarks}

$T_{1}$-Based agents are the first class of CAs historically investigated for CMR. These agents shorten the relaxation time of surrounding water protons, and are called "positive" agents because they produce image brightening in $T_{1}$-weighted imaging sequences. The paramagnetic $\mathrm{Gd}^{3+}$ has a high magnetic moment $\left(\mu^{2}=63\right.$ $\mathrm{BM}^{2}$ ) and is currently the metal ion of choice. However, free $\mathrm{Gd}^{3+}$ is well-known to be cytotoxic and retained in liver, spleen and bone. ${ }^{23-25}$ Due to its similarity with $\mathrm{Ca}^{2+}$ in atomic radius, $\mathrm{Gd}^{3+}$ also binds ion channels and biomolecules like calmodulin which mediates many crucial processes in the body such as metabolism, apoptosis, smooth muscle contraction, short-longterm memory and the immune response. To decrease its toxicity, the $\mathrm{Gd}^{3+}$ needs to be held tightly by an organic ligand to form stable complexes or chelates. Recent preclinical studies showed that paramagnetic $\mathrm{Mn}^{2+}$-based CAs have also emerged as safer alternatives and these are, potentially more compatible with renally compromised patients. ${ }^{26}$

Conventional, $T_{1}$-based CAs can be further divided into extracellular, blood pool, multinuclear CAs. These are all $T_{1}$-based, but differ in chemical structure, size and different number of $\mathrm{Gd}^{3+}$ per molecule.

4.1.1 Extracellular contrast agents. Extracellular CAs are so-called as they are not internalised by the body cells. Upon intravenous injection, these agents randomly distribute in intravascular and interstitial spaces and are excreted rapidly by the kidneys in their unchanged forms. Benefits include simple and inexpensive synthesis, relatively low toxicity and fast body clearance. The synthesis of these CAs involves chelation of the $\mathrm{Gd}^{3+}$ with acyclic or macrocyclic multidentate ligands containing multiple carboxylate anions (Fig. 1). The complexes are kinetically and thermodynamically stable, resulting in the minimal amount of free $\mathrm{Gd}^{3+}$ release in the body. The chemical
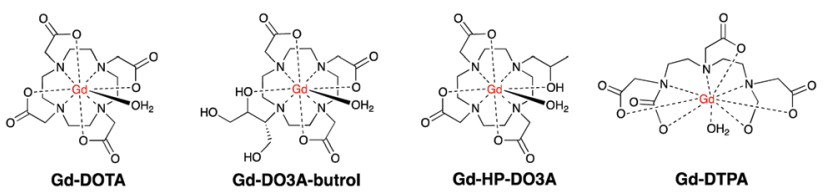

Fig. 1 First generation of $T_{1}$-based contrast agents used for CMR.

structure of the ligand plays a crucial role in the overall toxicity. ${ }^{27}$ CAs based on macrocyclic ligands (Gd-DOTA, Gd-DO3A butrol and Gd-HP-DO3A) are more stable compared to their acyclic counterparts based on Diethylene Triamine Pentaacetic Acid (Gd-DTPA) because the so-called macrocyclic effect lead to a lower release of free $\mathrm{Gd}^{3+}$ in the body.

Gd-DOTA showed enhancement on carotid vulnerable plaques related to inflammatory process ${ }^{28,29}$ as well as Gd-DTPA ${ }^{30,31}$ and Gd-DO3A-butrol, ${ }^{32}$ both at preclinical and clinical levels. Gd-DTPA also afforded enhanced contrast in the coronary artery wall of subjects after Acute Myocardium Infarction (AMI) compared to normal subjects six days after infarction. ${ }^{33}$ Since the introduction of Gd-DOTA in 1988, macrocyclic CAs have been extensively used to enhance the signal in CMR scans for the last three decades.

These agents also image non-cardiovascular related diseases like inflammatory edema and tumor angiogenesis. ${ }^{34}$ This may lead to false diagnosis of CVD, which prompts further development of CAs aimed specifically to damaged CVD.

4.1.2 Blood pool contrast agents. Blood pool is often referred to as a blood deposit that occurs on walls and valves of veins when they work ineffectively, thereby making it difficult for blood to return to the heart. Blood pool CAs are a valuable solution compared to the first generation of CAs. These agents are still extracellular and are specifically used for cardiovascular applications. The $T_{1}$-shortening capability in the damaged CVS was initially thought to be the main reason for the improved contrast. However, subsequent studies showed that such enhancement is also due to a higher molecular size which causes extended retention in the bloodstream; this results is a preferential absorption and passive accumulation of the CAs into atherosclerotic plaques via enhanced permeability and retention effect. ${ }^{35,36}$ This phenomenon is due to neovessels formation in the endothelial lesions during the atherosclerotic cascade. Given the growing importance of LGE in assessing damaged myocardium, ${ }^{37}$ research and development of such agents has been very intense. A recent example is gadofosveset (MS-325) ${ }^{8,38}$ which is currently used in patients ${ }^{39}$ with carotid artery stenosis for the detection of vulnerable plaque features. The superior capability of generating enhanced contrast was clearly demonstrated in a clinical trial, where LGE images of chronic myocardial infarction was compared using both MS-325 and Gd-DTPA. It was found that the accuracy of LGE was higher than MS-325 54 minutes after contrast injection, resulting in a sensitivity and specificity of $84 \%$ and $98 \%$ respectively. ${ }^{40}$ Another promising example is gadofluorine $M^{41}$ which affords enhanced images in aortic ${ }^{42,43}$ and femoral plaques of atherosclerotic rabbits. ${ }^{44}$ Independent studies ${ }^{45,46}$ demonstrated that upon injection in the bloodstream, gadofluorine M self-assembles in small micelles that bind the albumin present in 
the body, before penetrating into the atherosclerotic plaques; once there it passively accumulates in the fibrous cap.

Recent studies demonstrated that also gadofosveset, ${ }^{9} \mathrm{Gd}-\mathrm{B}-$ $22956 / 1^{47}$ and CB-Gd-DOTA-MA ${ }^{48}$ work via the same albuminbinding mechanism. In particular, Gd-B-22956/1 has a high affinity to serum albumin and generates high contrast enhancement in atherosclerotic plaques correlated with both neovessel and macrophages density. ${ }^{49}$ An improved novel blood pool CA, GdAAZTA-MADEC was recently developed and tested at a preclinical model, ${ }^{50}$ affording an enhanced contrast of damaged CVS compared to gadofosveset and B25716/1 at $1 \mathrm{~T}$. Herein, the presence of a hydrophobic spacer between the deoxycholic acid moiety and the Gd-AAZTA unit results in a stronger binding with albumin, hence affording a better contrast. Another promising contrast agent, P792, has been used for aortic arch and carotid imaging and is on phase III clinical development. ${ }^{51,52}$ Gd-DTPA-BMA allowed enhanced imaging of both necrotic core, calcification and loose matrix, all key components in unstable plaques. ${ }^{53}$ A comparative study on the morphological characterization of the carotid plaques has been carried out with Gd-BOPTA ${ }^{54}$ and Gd-DTPA-BMA, and it was found that the choice of the contrast agent has little impact. ${ }^{55}$ Other agents for enhanced contrast of vascular tissues and plaques identification are Gd-EOB-DTPA, ${ }^{56,57}$ Gd-Motexafin ${ }^{6}$ and Gd-AAZTA-C17. ${ }^{7}$ Fig. 2 shows some common blood pool CAs.

These findings suggest that chemists, clinicians and toxicologists will need to use these CAs as a lead to develop novel systems. It is anticipated that ligand design and synthesis will play a key role to obtain the next generation of blood pool CAs by further altering $T_{1}$ and increasing passive retention on damaged areas of CVS. ${ }^{58}$

So far, all CAs described herein have been designed to provide a contrast which is optimal for the vast majority of magnetic fields used in clinical CMR (up to $1.5 \mathrm{~T}$ ). Higher magnetic fields severely compromise image contrast as $T_{1}$ is reduced up to one-third compared to its maximum. This feature could be a long term limitation, given the recent advents of high field clinical scanners (3 $\mathrm{T})$.

On the other hand, higher field MRI introduces serious safety considerations: higher power radiofrequency pulses, potential tissue heating, coil burns and, most prominently, the dangers associated with a stronger magnetic field, such as ferromagnetic materials and implanted medical devices in the patients, many of which have not been evaluated at fields above $1.5 \mathrm{~T}$.

Given these limitations there is still an enormous effort to develop alternative CAs to provide enhanced contrast with 1.5 T-based clinical scanners.

4.1.3 Multinuclear contrast agents. A recent and promising solution are the so-called multinuclear CAs. Different from the aforementioned CAs, these agents contain more than one $\mathrm{Gd}^{3+}$ centre per molecule and have some advantages compared to their mononuclear counterparts. Their higher molecular weight allows a better retention in atherosclerotic plaques, ${ }^{59}$ whereas the presence of multiple $\mathrm{Gd}^{3+}$ centers will be more efficient in altering $T_{1}$.

One of the most advanced CAs in clinical development is Gadomer $17^{60}$ (Fig. 3, page 6), which is a dendritic chelate carrying $24 \mathrm{Gd}^{3+}$ centers. ${ }^{10,61,62}$
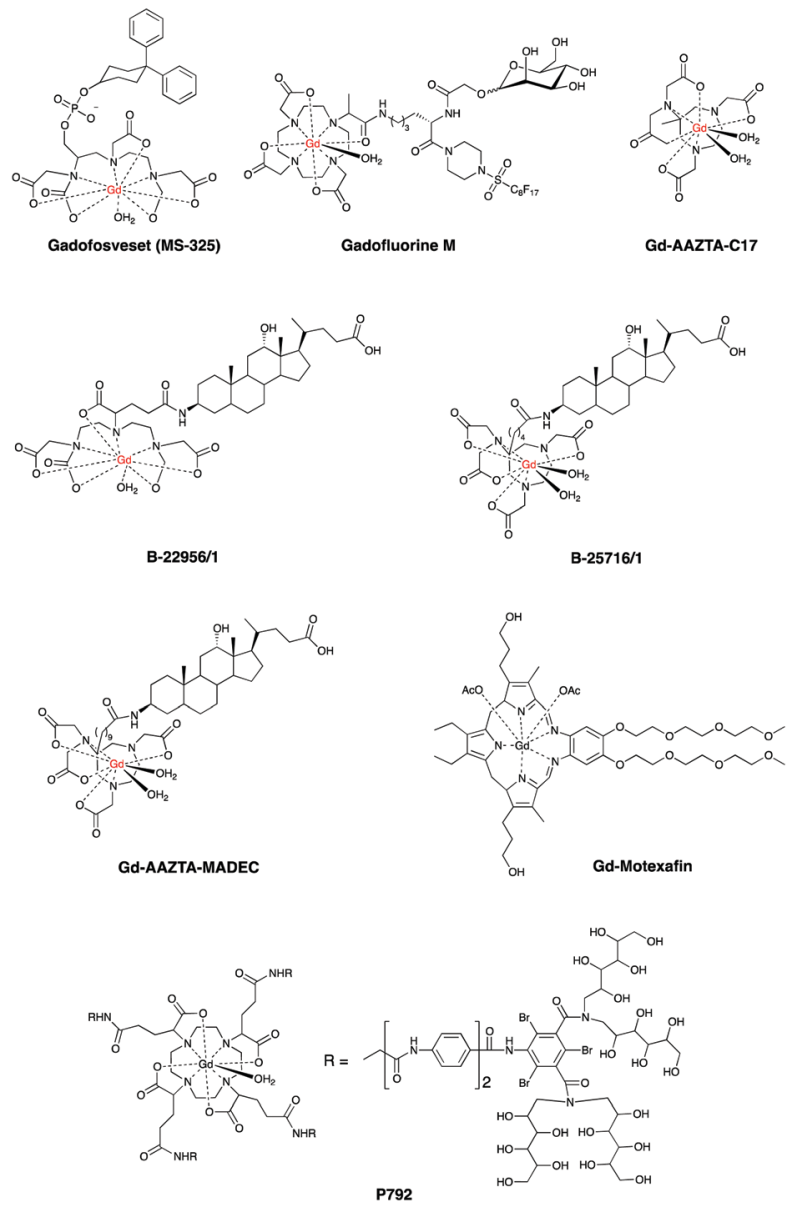

Fig. 2 Most common blood pool contrast CAs for clinical and preclinical CMR.

After intravenous injection Gadomer-17 distributes almost exclusively within the intravascular space, providing enhanced contrast of coronary arteries in patients with Coronary Artery Disease $(\mathrm{CAD})^{63}$ and in a swine model of myocardial perfusion. ${ }^{5}$

Another example is MPEG-polylysine-DTPA-Gd3 for an enhanced vessel-muscle contrast where the half-life was shown to be $14 \mathrm{~h}$ with a dose of $20 \mu \mathrm{mol}$ of $\mathrm{Gd}$ per $\mathrm{kg}$ in preclinical trials. $^{64}$

Similar to blood pool CAs, the molecular size of multinuclear CAs is too large for capillary extravasation, yet it is small enough for rapid renal elimination, allowing improved images of vessels and decreased toxicity compared to their mononuclear counterparts. Polynuclear micelles containing Gd-DOTAC16, Gd-DTPA-BSA or Gd-DO3A-OA (Fig. 4) have also been prepared and gave enhanced images of macrophages in plaques compared to standard mononuclear agents such as Gd-DTPA. ${ }^{65,66}$ In another study high density lipoproteins (HDL) containing Gd-DTPA-DMPE showed enhanced imaging of atherosclerotic lesions. ${ }^{67-69}$

Whilst multinuclear CAs may allow enhanced images of damaged CVS, they also pose serious issues due to potential release of more free $\mathrm{Gd}^{3+}$ in liver, spleen and bones, ${ }^{70}$ requiring longer and more expensive toxicology tests before their translation 


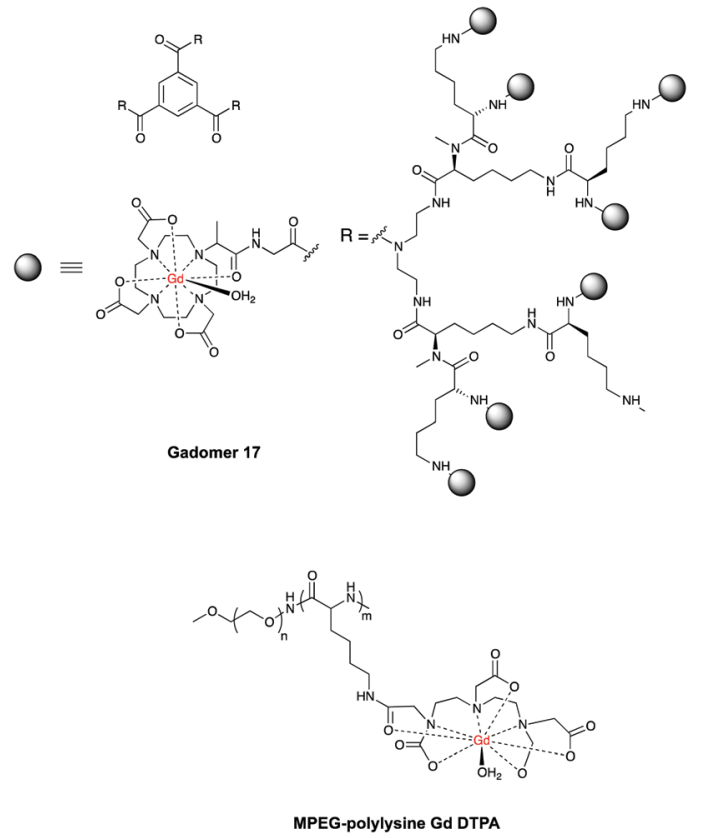

Fig. 3 Structures of Gadomer 17 and MPEG polylysine DTPA polymers.

into clinical uses. The use of biodegradable multinuclear CAs can be a safer alternative. Preclinical studies showed that after providing enhanced contrast of heart and blood vessels, endogenous enzymes in the body will degrade these CAs into lower molecular weight fragments, which are more easily excreted by the kidneys. ${ }^{71-74}$

\section{2. $T_{2}$-Based contrast agents}

4.2.1 General remarks. $T_{2}$-Based CAs mainly shorten the transverse relaxation times of the surrounding water protons and are termed "negative" agents because they produce darker images in $T_{2}$-weighted imaging sequences.

The ability of iron oxide nanoparticles to alter $T_{2}$ relaxation times in water was first discovered in $1978 .^{75}$ Since then iron oxide became the most common $T_{2}$-based CA currently used. Super Paramagnetic Iron Oxide Nanoparticles (SPIONS, diameter size 50 to $300 \mathrm{~nm}$ ) and Ultra-small SPIONS (USPIONS, diameter size 15 to $30 \mathrm{~nm}$ ) are iron oxide nanoparticles that can be coated with dextran, silicates, or other non-immunogenic polymers for preclinical and clinical applications. An advantage of SPIONS
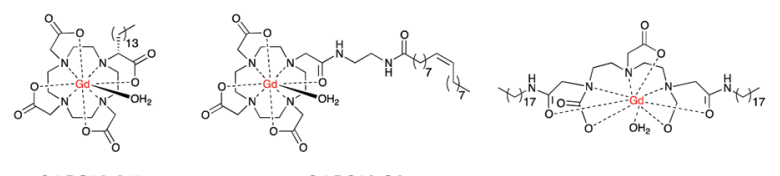

Gd-DO3A-C16

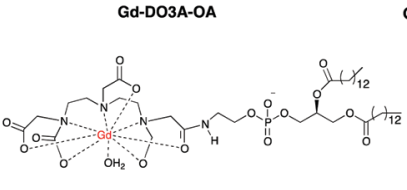

Gd-DTPA-BSA

Gd-DTPA-DMPE

Fig. 4 Multinuclear contrast agents currently developed for CMR. over $T_{1}$-based CAs is their transverse relaxivity which increases at higher fields. This property suggests that SPIONS can be a promising tool for the future, especially with the advent of high field MRI. Additionally, unlike Gd-based CAs, SPIONS have proven safe and are cleared as endogenous iron by the reticuloendothelial system.

There are many different system containing SPIONS for CVDs. $^{76-79}$ The next sections will describe them separately, along with recent advances, current challenges and future directions.

4.2.2 Non-specific contrast reagents: SPIONS. Non-specific SPIONS are primarily addressed to macrophages which accumulate in atherosclerotic lesions and promote the late stage formation of atheroma and atherosclerotic plaques rupture. ${ }^{80}$

To date, ferumoxtran is one of the most extensively studied CAs for imaging atherosclerotic plaques, both at preclinical and clinical levels. ${ }^{81,82}$ Ferumoxtran offers a number of advantages: inexpensive synthesis, very good biocompatibility, high affinity for plaque macrophages and a low toxicity. It has been successfully applied to enhance images in stenotic carotid or atheromatous plaques. ${ }^{81-83}$ In another study ${ }^{84}$ ferumoxtran has been administered for CMR imaging of symptomatic patients scheduled for carotid endarterectomy, showing enhanced contrast (up to 25\%) and high SPION content (up to $75 \%$ ) in rupture-prone lesions, as confirmed by histology. The optimal post-injection time for imaging symptomatic plaques was found to be between 24 and 36 h. ${ }^{81}$ The high reliability of ferumoxtran has been used for therapy monitoring in patients treated with different doses of atorvastatin. ${ }^{85,86}$ Another SPION based agent, Sinerem, also proved very promising in providing enhanced images of macrophages in atherosclerotic plaques of rabbits. ${ }^{87}$

Despite providing enhanced images of damaged CVS, these CAs lack of tissue specificity. Ferumoxtran is a polysaccharidecoated SPION and can be easily internalized by the macrophages present in other tissues of the body, in particular by the Kupffer cells in the liver. ${ }^{88}$ Synthetic challenges also arise from controlling the size of the SPIONs, a key factor. Studies showed that smaller nanoparticles (up to $5 \mathrm{~nm}$ ) would be more advantageous for easier body clearance and decreased toxicity. ${ }^{89-91}$ Phagocytic cells internalize large particles more effectively, whereas nonphagocytic $\mathrm{T}$ cells internalize intermediate-sized particles more efficiently. ${ }^{92-94}$

To increase the CVS specificity, many research groups investigated different sizes of SPIONS and polymer-coating chemicals. Mannan ${ }^{95}$ coated SPIONS allowed enhanced images of atherosclerotic walls in rabbits, ${ }^{96}$ whereas citrate ${ }^{97}$ and Dextran Sulphate (DS) coated SPIONS provided enhanced contrast of atherosclerotic plaques both in preclinical and clinical studies. ${ }^{98}$

\section{Molecular imaging of CVDs: the emerging role of molecular contrast reagents}

\subsection{General remarks}

Molecular imaging is able to visualize specific biomolecules expressed during a broad range of pathologies. This technique 
has been increasingly applied to detect CVDs as many biomolecules are expressed de novo during inflammation and endothelial dysfunction. The most important biomolecules known so far are $\mathrm{E}$ and P-selectins, integrins, Vascular Cell Adhesion Molecule 1 (VCAM-1), Intercellular Adhesion Molecule 1 (ICAM-1), peroxidases and Matrix Metalloproteinases (MMPs). These molecules promote leukocyte rolling and adhesion on the wall of the inflamed endothelium and their subsequent transmigration into the sub-endothelial space, all important events in the development of CVDs (Fig. 5). ${ }^{99-101}$

Integrin $\alpha_{v} \beta_{3}$ promotes leucocyte extravasation through the extracellular matrix and is heavily involved in atherosclerosis progression and in restenosis. MMPs are a broad family of endopeptidases involved in rupture-prone plaques and play a key role in the degradation and remodelling of the extracellular matrix. Myeloperoxidases (MPO) promote oxidation of low-density lipoprotein (LDL). ${ }^{102}$ Fibrin is also an important component of atherosclerotic plaques and is present in advanced lesions, whereas elastin is important in vascular remodelling. Lowdensity Lipoprotein Receptor-1 (LOX-1) triggers inflammation in the endothelium and is expressed in vulnerable plaques.

\subsection{Molecular $T_{1}$-based contrast agents}

Targeted $T_{1}$-based CAs are made by linking three components: the first one is a targeting vector which binds the biomolecule of interest, the second one is a clinical $T_{1}$ based CA which provides the contrast, and the third one is a linker which holds the first two components together. ${ }^{103}$ The chemical process aimed to link these components together is called bioconjugation, which generally results in the formation of biologically stable molecular moieties like amides, ethers or thioesters. The enhanced contrast of these CAs derives from both $T_{1}$ alteration and the specificity of the CA for the biomolecule of interest (Fig. 6). The mode of action is different from the conventional CAs (described in Section 4) which are not targeted to any molecule but accumulate passively in the damaged CVS.

Compared to conventional CAs, molecular CAs offer many advantages: better specificity, improved contrast and a better

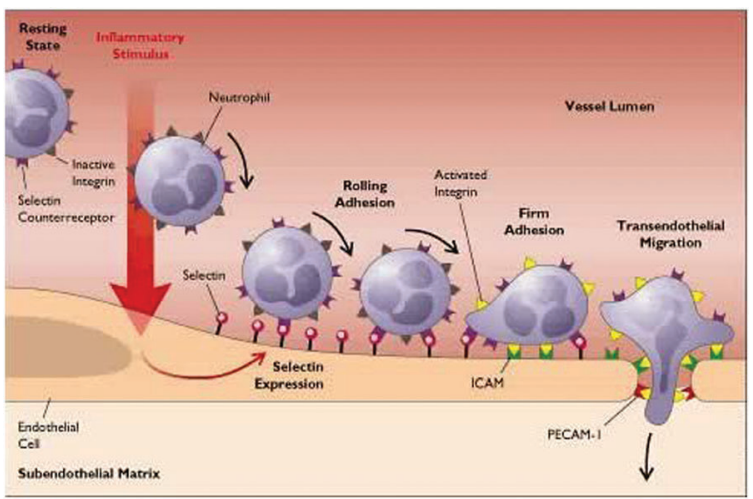

Fig. 5 The beginning of atherosclerosis. Following an inflammatory response, $\mathrm{E}$ and $\mathrm{P}$ selectins are expressed and translocated on the endothelial surface, causing leucocytes in the blood stream (blue) to tether, roll and accumulate on the endothelium, triggering the formation of atherosclerotic plaques. understanding of molecular processes behind CVDs. Clinicians and medicinal chemists will use these advantages to develop better drugs and improved therapies. Long term advantages are also detection of CVDs at subclinical levels, identification of in vivo markers for stable and unstable plaques and patientindividualised risk assessment.

Despite the great promise, many challenges still hamper the translation of molecular CAs into clinical use: complex multistep syntheses and optimisation processes are often needed. To obtain the best contrast, bioconjugation must not alter the affinity of the vector for the targeted biomolecule or decrease the probe capability to alter $T_{1}$. In case of Gd-based molecular CAs, bioconjugation may also lead to the release of free Gd in the body, requiring longer and more expensive toxicology studies.

Given these challenges, research in this field has been very intense and there is a plethora of systems already reported, examples include $\mathrm{E}$ and P-selectin imaging with Gd-F-P717, Gd-P717 ${ }^{104-107}$ and Gd-DTPA-BsLexA, respectively. ${ }^{108,109}$ A targeted Gd-based contrast agent was used to image MMPs activation ${ }^{110}$ as well as fibrin ${ }^{111-113}$ with Gd EP-2104R ${ }^{114}$ and EP-1242. ${ }^{115}$ Gd-LMI1174 ${ }^{116}$ and BMS753951 $1^{117}$ allowed enhanced images of plaques by targeting elastin and has been used to quantify the changes in elastin content in plaques regression in a mouse model of atherosclerosis. Targeted liposomes containing Gd-DTPA successfully imaged low density lipoprotein receptors in $\operatorname{ApoE}(-/-)$ mice. ${ }^{118,119}$
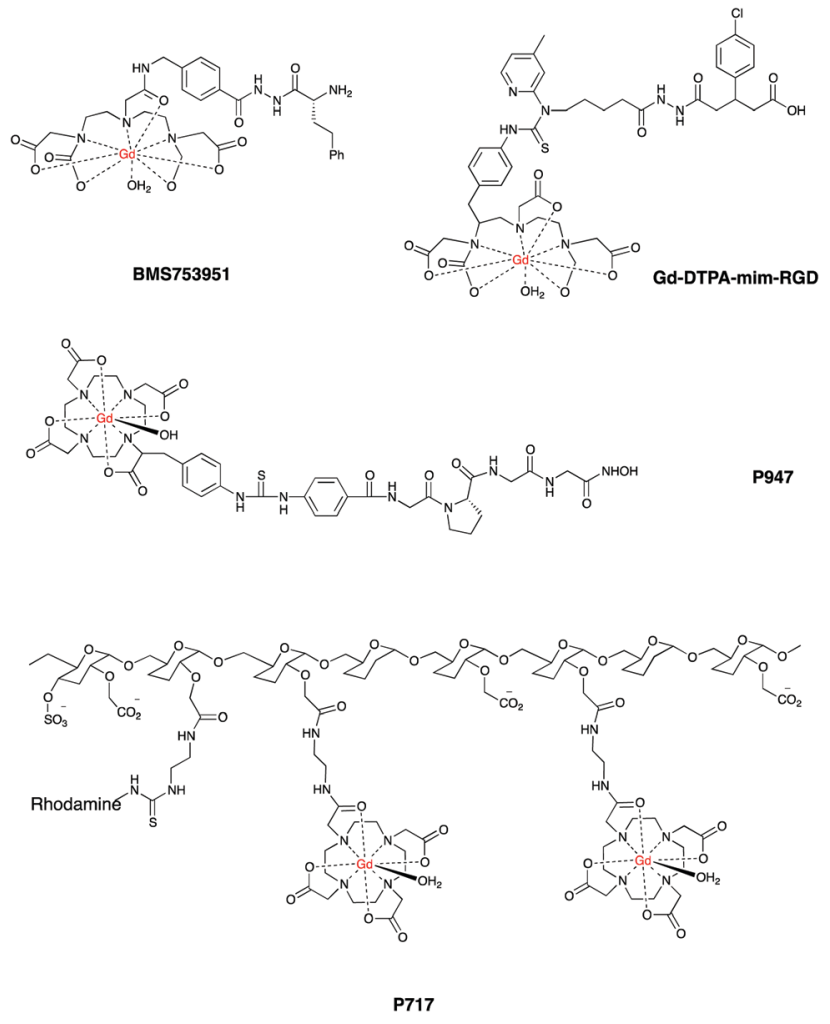

Fig. 6 Some $T_{1}$-based targeted contrast agents currently in preclinical development. 
Gd-DTPA-G-R826 is a conjugate containing the peptide sequence LIKKPF: this agent binds the phosphatidylserine receptor of apoptotic macrophages, allowing enhanced images of atherosclerotic plaques. ${ }^{120}$ A similar peptide-based agent has been reported to image plaque progression. ${ }^{121}$

Another group developed a Gd-DTPA-mim-RGD agent that allowed enhanced images of inflamed blood vessels by targeting integrin $\alpha_{v} \beta_{3}$ in vulnerable atherosclerotic plaques. The authors also reported a decreased contrast when the analogue, nontargeted Gd-DTPA was used in the same model. ${ }^{122}$

Contrast agents containing amphiphilic fullerenes $\mathrm{C}_{60},{ }^{123}$ $\mathrm{C}_{70}{ }^{124}$ have also been recently developed, providing enhanced visualization of specific receptors on foam cells in atherosclerotic plaques compared to mononuclear Gd-DOTA. ${ }^{125}$

In a similar fashion, Gd-DTPA-MPO provided enhanced contrast by targeting myeloperoxidase activity in mice. ${ }^{126}$ Finally, P947 is a Gd-DOTA derived agent that afforded enhanced images by targeting the MMPs that accumulate in atherosclerotic lesions. ${ }^{127,128}$ Fig. 6 shows some promising CAs for targeted CMR.

\subsection{Molecular $T_{2}$-based contrast agents}

Similar to what has been discussed for $T_{1}$-based molecular CAs, SPIONS can be targeted to specific biomolecules involved in CVDs. This can be achieved by synthetically modifying the SPIONS coating to allow attachment of targeting vectors. The resulting CAs offer enhanced images of CVS, improved bioavailability and lower toxicity. All these features can facilitate the translation of these systems into clinical use.

The synthetic challenges described in Section 5.2 also apply for molecular $T_{2}$-based CAs. For these CAs, bioconjugation and formulation constitute even more critical steps as they may cause self-aggregation and precipitation of insoluble CAs both in vitro and in vivo. As nanoparticle-based CAs translate into the clinic, one additional challenge is to maximize the value-to-cost ratio for high volume product scale-up.

Research in this field has been intense, recent examples (Table 1) are contrast agent VINP-28, a peptide-bound nanoparticle with high affinity for VCAM-1 that afforded enhanced contrast in the aortic root of ApoE-/- mice 48 hours after injection. ${ }^{129}$ The contrast obtained with VINP-28 has been also used for therapy monitoring where the enhanced signal in atherosclerotic plaques strongly decreased after an 8 week treatment with Statin. Further examples of VCAM-1 targeted imaging with SPIONS have been published. ${ }^{130,131}$

SPIONS have also been conjugated with antibodies and with a SLex mimics ${ }^{133,134}$ to detect E-selectins and CD44, both celladhesion molecules involved in the early stages of atherosclerosis

Table 1 Targeted SPIONS currently investigated in preclinical studies

\begin{tabular}{lll}
\hline Name & Ref. & Molecular target \\
\hline VINP-28 & 129 & VCAM-1 \\
SPIONS-antibodies & 133 & E-selectin, CD44 \\
SPIONS-SLeX mimic & 134 & E-selectin, CD44 \\
SPIONS-fumagillin & 136 and 137 & Integrin \\
SPIONS-annexin & 132 & Phosphatidyl serine
\end{tabular}

\section{References}

1 S. Mendis, P. Puska and B. Norrving, Global atlas on cardiovascular disease prevention and control, World Health Organization, 2011.

2 P. Mansfield and A. A. Maudsley, Br. J. Radiol., 1977, 50, 188-194. 
3 C. Lang and M. K. Atalay, R. I. Med. J., 2014, 97, 28-34.

4 J. C. Bousquet, S. Saini, D. D. Stark, P. F. Hahn, M. Nigam, J. Wittenberg and J. T. Ferrucci, Jr., Radiology, 1988, 166, 693-698.

5 P. Kellman, M. S. Hansen, S. Nielles-Vallespin, J. Nickander, R. Themudo, M. Ugander and H. Xue, J. Cardiovasc. Magn. Reson., 2017, 19, 43.

6 K. Ramani, R. M. Judd, T. A. Holly, T. B. Parrish, V. H. Rigolin, M. A. Parker, C. Callahan, S. W. Fitzgerald, R. O. Bonow and F. J. Klocke, Circulation, 1998, 98, 2687-2694.

7 T. A. Treibel, S. K. White and J. C. Moon, Curr. Cardiovasc. Imaging Rep., 2014, 7, 9254.

8 S. Kelle, T. Thouet, T. Tangcharoen, K. Nassenstein, A. Chiribiri, I. Paetsch, B. Schnackenburg, J. Barkhausen, E. Fleck and E. Nagel, Med. Sci. Monit., 2007, 13, 469-474.

9 R. B. Lauffer, D. J. Parmelee, S. U. Dunham, H. S. Ouellet, R. P. Dolan, S. Witte, T. J. McMurry and R. C. Walovitch, Radiology, 1998, 207, 529-538.

10 M. Brechbiel, K. Jaspers, B. Versluis, T. Leiner, P. Dijkstra, M. Oostendorp, J. M. van Golde, M. J. Post and W. H. Backes, PLoS One, 2011, 6, e16159.

11 P. U. Atukorale, G. Covarrubias, L. Bauer and E. Karathanasis, Adv. Drug Delivery Rev., 2016, DOI: 10.1016/j.addr.2016.09.006.

12 W. J. Manning and D. J. Pennell, in Basic principles of cardiovascular magnetic resonance. Cardiovascular magnetic resonance, Saunders, Philadelphia, 2010, vol. 2, pp. 3-18.

13 T. F. Hany, M. Schmidt, P. R. Hilfiker, P. Steiner, U. Bachmann and J. F. Debatin, J. Magn. Reson. Imaging, 1998, 8, 901-906.

14 M. F. Bellin and A. J. Van Der Molen, Eur. J. Radiol., 2008, 66, 160-167.

15 T. Frenzel, P. Lengsfeld, H. Schirmer, J. Hutter and H. J. Weinmann, Invest. Radiol., 2008, 43, 817-828.

16 F. G. Shellock and E. Kanal, J. Magn. Reson. Imaging, 1999, 10, 477-484.

17 C. Olchowy, K. Cebulski, M. Lasecki, R. Chaber, A. Olchowy, K. Kalwak and U. Zaleska-Dorobisz, PLoS One, 2017, 12, e0171704.

18 T. Kanda, K. Ishii, H. Kawaguchi, K. Kitajima and D. Takenaka, Radiology, 2013, 270, 834-841.

19 T. Kanda, Y. Nakai, H. Oba, K. Toyoda, K. Kitajima and S. Furui, Magn. Reson. Imaging, 2016, 34, 1346-1350.

20 O. P. Simonetti, R. J. Ki, D. S. Fien, H. B. Hillenbrand, E. Wu, J. M. Bundy, J. P. Finn and R. M. Judd, Radiology, 2001, 218, 215-223.

21 A. Doltra, B. H. Amundsen, R. Gebker, E. Fleck and S. Kelle, Curr. Cardiol. Rev., 2013, 3, 185-190.

22 F. Dioury, A. Duprat, G. Dreyfus, C. Ferroud and J. Cossy, J. Chem. Inf. Model., 2014, 54, 2718-2731.

23 K. N. Christensen, C. U. Lee, M. M. Hanley, N. Leung, T. P. Moyer and M. R. Pittelkow, J. Am. Acad. Dermatol., 2011, 64, 91-96.

24 World Health Organization. Pharmaceuticals: Restrictions in Use and Availability, WHO/EMP/QSM/2010.3, Geneva, Switzerland, 2010, p. 14.

25 C. D. Wiginton, B. Kelly, A. Oto, M. Jesse, P. Aristimuno, R. Ernst and G. Chaljub, Am. J. Roentgenol., 2008, 190, 1060-1068.
26 E. M. Gale, I. P. Atanasova, F. Blasi, I. Ay and P. Caravan, J. Am. Chem. Soc., 2015, 137, 15548-15557.

27 A. K. Tiwari, H. Ojha, A. Kaul, A. Dutta, P. Srivastava, G. Shukla, R. Srivastava and A. K. Mishra, Chem. Biol. Drug Des., 2009, 74, 87-91.

28 A. Millon, L. Boussel, M. Brevet, J. L. Mathevet, E. CanetSoulas, C. Mory, J. Y. Scoazec and P. Douek, Stroke, 2012, 43, 3023-3028.

29 L. Boussel, G. Herigault, M. Sigovan, R. Loffroy, E. CanetSoulas and P. C. Douek, J. Magn. Reson. Imaging, 2008, 28, 533-537.

30 A. Phinikaridou, F. L. Ruberg, K. J. Hallock, Y. Qiao, N. Hua, J. Viereck and J. A. Hamilton, Circ. Cardiovasc. Imaging, 2010, 3, 323-332.

31 J. A. Ronald, Y. Chen, A. J. L. Belisle, A. M. Hamilton, K. A. Rogers, R. A. Hegele, B. Misselwitz and B. K. Rutt, Circ. Cardiovasc. Imaging, 2009, 2, 226-234.

32 J. M. Grimm, K. Nikolaou, A. Schindler, R. Hettich, F. Heigl, C. C. Cyran, F. Schwarz, R. Klingel, A. Karpinska, C. Yuan, M. Dichgans, M. F. Reiser and T. Saam, J. Cardiovasc. Magn. Reson., 2012, 14, 80.

33 T. Ibrahim, M. R. Makowski, A. Jankauskas, D. Maintz, M. Karch, S. Schachoff, W. J. Manning, A. Schömig, M. Schwaiger and R. M. Botnar, JACC: Cardiovasc. Imaging, 2009, 2, 580-588.

34 H. Hawighorst, P. G. Knapstein, M. V. Knopp, P. Vaupel and G. van Kaick, MAGMA, 1999, 8, 55-62.

35 E. Lobatto, V. Fuster, Z. A. Fayad and W. J. M. Mulder, Nat. Rev. Drug Discovery, 2011, 10, 835-852.

36 J. Fang, H. Nakamura and H. Maeda, Adv. Drug Delivery Rev., 2011, 63, 136-151.

37 A. Varga-Szemes, R. J. van der Geest, B. S. Spottiswoode, P. Suranyi, B. Ruzsics, C. N. De Cecco, G. Muscogiuri, P. M. Cannaò, M. A. Fox, J. L. Wichmann, R. Vliegenthart and U. I. Schoepf, Radiology, 2015, 278, 374-382.

38 P. Caravan, J. J. Ellison, T. J. McMurry and R. B. Lauffer, Chem. Rev., 1999, 99, 2293-2352.

39 S. Tartari, R. Rizzati, R. Righi, A. Deledda, K. Capello, R. Soverini and G. Benea, Am. J. Roentgenol., 2011, 196, 1164-1171.

40 T. Thouet, B. Schnackenburg, T. Kokocinski, E. Fleck, E. Nagel and S. Kelle, Sci. World J., 2012, 2012, 1-6.

41 M. Sirol, P. R. Moreno, K. R. Purushothaman, E. Vucic, V. Amirbekian, H.-J. Weinmann, P. Muntner, V. Fuster and Z. A. Fayad, Circ. Cardiovasc. Imaging, 2009, 2, 391.

42 M. Sirol, V. V. Itskovich, V. Mani, J. G. S. Aguinaldo, J. T. M. Fallon, B. Misselwitz, H. J. Weinmann, V. Fuster, J. F. Toussaint and Z. A. Fayad, Circulation, 2004, 109, 2890-2896.

43 J. Barkhausen, W. Ebert, C. Heyer, J. F. Debatin and H.-J. Weinmann, Circulation, 2003, 108, 605-609.

44 J. Zheng, E. Ochoa, B. Misselwitz, D. Yang, I. El Naqa, P. K. Woodard and D. Abendschein, Invest. Radiol., 2008, 43, 49-52.

45 J. Meding, M. Urich, K. Licha, M. Reinhardt, B. Misselwitz, Z. A. Fayad and H. J. Weinmann, Contrast Media Mol. Imaging, 2007, 2, 120-129. 
46 R. Uppal and P. Caravan, Future Med. Chem., 2010, 2, 451-470. 47 C. Parolini, M. Busnelli, G. S. Ganzetti, F. Dellera, S. Manzini, E. Scanziani, J. L. Johnson, C. R. Sirtori and G. Chiesa, Mol. Imaging, 2014, 13, 1-9.

48 L. N. Goswami, Q. Cai, L. Ma, S. S. Jalisatgi and M. F. Hawthorne, Org. Biomol. Chem., 2015, 13, 8912-8918.

49 J. C. Cornily, F. Hyafil, C. Calcagno, K. C. Briley-Saebo, J. Tunstead, J. G. S. Aguinaldo, V. Mani, V. Lorusso, F. M. Cavagna and Z. A. Fayad, J. Magn. Reson. Imaging, 2008, 27, 1406-1411.

50 D. L. Longo, F. Arena, L. Consolino, P. Minazzi, S. GeninattiCrich, G. B. Giovenzana and S. Aime, Biomaterials, 2016, 75, 47-57.

51 L. Vander Elst, I. Raynal, M. Port, P. Tisnès and R. N. Muller, Eur. J. Inorg. Chem., 2005, 1142-1148.

52 H. Alsaid, M. Sabbah, Z. Bendahmane, O. Fokapu, J. Felblinger, C. Desbleds-Mansard, C. Corot, A. Briguet, Y. Crémillieux and E. Canet-Soulas, Magn. Reson. Med., 2007, 58, 1157-1163.

53 W. Liu, N. Balu, J. Sun, X. Zhao, H. Chen, C. Yuan, H. Zhao, J. Xu, G. Wang and W. S. Kerwin, J. Magn. Reson. Imaging, 2012, 35, 812-819.

54 F. Uggeri, S. Aime, P. L. Anelli, M. Botta, M. Brocchetta, C. de Haeen, G. Ermondi, M. Grandi and P. Paoli, Inorg. Chem., 1995, 34, 633-643.

55 W. S. Kerwin, X. Zhao, C. Yuan, T. S. Hatsukami, K. R. Maravilla, H. R. Underhill and X. Zhao, J. Magn. Reson. Imaging, 2009, 30, 35-40.

56 G. Schuhmann-Giampieri, H. Schmitt-Willich, W. R. Press, C. Negishi, H. J. Weinmann and U. Speck, Radiology, 1992, 183, 59-64.

57 L. V. Elst, F. Maton, S. Laurent, F. Seghi, F. Chapelle and R. N. Muller, Magn. Reson. Med., 1997, 38, 604-614.

58 G. H. Lee, Y. Chang and T. J. Kim, Eur. J. Inorg. Chem., 2012, 1924-1933.

59 A. N. Oksendal and P.-A. Hals, J. Magn. Reson. Imaging, 1993, 3, 157-165.

60 B. Misselwitz, H. Schmitt-Willich, W. Ebert, T. Frenzel and H. J. Weinmann, MAGMA, 2001, 128-134.

61 J. Tang, Y. Sheng, H. Hu and Y. Shen, Prog. Polym. Sci., 2013, 38, 462-502.

62 S. Langereis, A. Dirksen, T. M. Hackeng, M. H. P. van Genderen and E. W. Meijer, New J. Chem., 2007, 31, 1152-1160.

63 G. A. Krombach, C. B. Higgins, M. Chujo and M. Saeed, Radiology, 2005, 236, 510-518.

64 A. A. Bogdanov, R. Weissleder, H. W. Frank, A. V. Bogdanova, N. Nossif, B. K. Schaffer, E. Tsai, M. I. Papisov and T. J. Brady, Radiology, 1993, 187, 701-706.

65 M. J. Lipinski, V. Amirbekian, J. C. Frias, J. G. S. Aguinaldo, V. Mani, K. C. Briley-Saebo, V. Fuster, J. T. Fallon, E. A. Fisher and Z. A. Fayad, Magn. Reson. Med., 2006, 56, 601-610.

66 W. Chen, D. P. Cormode, Y. Vengrenyuk, B. Herranz, J. E. Feig, A. Klink, W. J. M. Mulder, E. A. Fisher and Z. A. Fayad, JACC: Cardiovasc. Imaging, 2013, 6, 373-384.

67 K. C. Briley-Saebo, S. Geninatti-Crich, D. P. Cormode, A. Barazza, W. J. M. Mulder, W. Chen, G. B. Giovenzana,
E. A. Fisher, S. Aime and Z. A. Fayad, J. Phys. Chem. B, 2009, 113, 6283-6289.

68 K. C. Briley-Saebo, V. Amirbekian, V. Mani, J. G. S. Aguinaldo, E. Vucic, D. Carpenter, S. Amirbekian and Z. A. Fayad, Magn. Reson. Med., 2006, 56, 1336-1346.

69 J. C. Frias, K. J. Williams, E. A. Fisher and Z. A. Fayad, J. Am. Chem. Soc., 2004, 126, 16316-16317.

70 S. Aime and P. Caravan, J. Magn. Reson. Imaging, 2009, 30, 1259-1267.

71 Z. R. Lu, A. M. Mohs, Y. Zong and Y. Feng, Int. J. Nanomed., 2006, 1, 31-40.

72 A. M. Mohs, Y. Zong, J. Guo, D. L. Parker and Z.-R. Lu, Biomacromolecules, 2005, 6, 2305-2311.

73 A. M. Mohs, X. Wang, K. C. Goodrich, Y. Zong, D. L. Parker and Z. R. Lu, Bioconjugate Chem., 2004, 15, 1424-1430.

74 T. D. Nguyen, P. Spincemaille, A. Vaidya, M. R. Prince, Z.-R. Lu and Y. Wang, Mol. Pharmaceutics, 2006, 3, 558-565.

75 M. Ohgushi, K. Nagayama and A. Wada, J. Magn. Reson., 1978, 29, 599-601.

76 E. A. Schellenberger, A. Bogdanov, Jr, D. Hogemann, J. Tait, R. Weissleder and L. Josephson, Mol. Imaging, 2002, 1, 102-107.

77 P. Bannas, O. Graumann, P. Balcerak, K. Peldschus, M. G. Kaul, H. Hohenberg, F. Haag, G. Adam, H. Ittrich and F. Koch-Nolte, Mol. Imaging, 2010, 9, 211-222.

78 H. B. Na, I. C. Song and T. Hyeon, Adv. Mater., 2009, 21, 2133-2148.

79 T. C. Yeh, W. Zhang, S. T. Ildstad and C. Ho, Magn. Reson. Med., 1993, 30, 617-625.

80 P. Libby, Circulation, 2001, 104, 365-372.

81 R. A. Trivedi, J. M. U-King-Im, M. J. Graves, P. J. Kirkpatrick and J. H. Gillard, Neurology, 2004, 63, 187-188.

82 S. A. Schmitz, M. Taupitz, S. Wagner, K. J. Wolf, D. Beyersdorff and B. Hamm, J. Magn. Reson. Imaging, 2001, 14, 355-361.

83 R. A. Trivedi, J. M. U-King-Im, M. J. Graves, J. J. Cross, J. Horsley, M. J. Goddard, J. N. Skepper, G. Quartey, E. Warburton, I. Joubert, L. Wang, P. J. Kirkpatrick, J. Brown and J. H. Gillard, Stroke, 2004, 35, 1631-1635.

84 M. E. Kooi, V. C. Cappendijk, K. B. J. M. Cleutjens, A. G. H. Kessels, P. J. E. H. M. Kitslaar, M. Borgers, P. M. Frederik, M. J. A. P. Daemen and J. M. A. van Engelshoven, Circulation, 2003, 107, 2453-2458.

85 T. Y. Tang, S. P. S. Howarth, S. R. Miller, M. J. Graves, A. J. Patterson, J. M. U-King-Im, Z. Y. Li, S. R. Walsh, A. P. Brown, P. J. Kirkpatrick, E. A. Warburton, P. D. Hayes, K. Varty, J. R. Boyle, M. E. Gaun, A. Zalewski and J. H. Gillard, J. Am. Coll. Cardiol., 2009, 53, 2039-2050.

86 J. H. F. Rudd, F. Hyafil and Z. A. Fayad, Arterioscler., Thromb., Vasc. Biol., 2009, 29, 1009-1016.

87 S. G. Ruehm, C. Corot, P. Vogt, S. Kolb and J. F. Debatin, Circulation, 2001, 103, 415-422.

88 Z. Zhang, N. Mascheri, R. Dharmakumar and D. Li, Cytotherapy, 2008, 10, 575-586.

89 H. S. Choi, W. Liu, P. Misra, E. Tanaka, J. P. Zimmer, B. Itty Ipe, M. G. Bawendi and J. V. Frangioni, Nat. Biotechnol., 2007, 25, 1165-1170. 
90 P. C. Naha, K. C. Lau, J. C. Hsu, M. Hajfathalian, S. Mian, P. Chhour, L. Uppuluri, E. S. McDonald, A. D. Maidment and D. P. Cormode, Nanoscale, 2016, 8, 13740-13754.

91 P. C. Naha, A. A. Zaki, E. Hecht, M. Chorny, P. Chhour, E. Blankemeyer, D. M. Yates, W. R. Witschey, H. I. Litt, A. Tsourkas and D. P. Cormode, J. Mater. Chem. B, 2014, 2, 8239-8248.

92 R. D. Oude Engberink, S. M. A. van der Pol, E. A. Döpp, H. E. de Vries and E. L. A. Blezer, Radiology, 2007, 243, 467-474.

93 Z. Zhang, E. J. van de Bosv, P. Wielopolski, M. de JongPopijus, M. Bernsen, D. Duncker and G. Krestin, MAGMA, 2005, 18, 175-185.

94 D. L. J. Thorek and A. Tsourkas, Biomaterials, 2008, 29, 3583-3590.

95 K. Tsuchiya, N. Nitta, A. Sonoda, H. Otani, M. Takahashi, K. Murata, M. Shiomi, Y. Tabata and S. Nohara, Eur. J. Radiol., 2013, 82, 1919-1925.

96 Y. M. Kyong, P. I. Young, I. Y. Kim, I. K. Park, K. J. S. Kwon, H. J. Jeong, Y. Y. Jeong and C. C. Su, J. Nanosci. Nanotechnol., 2008, 8, 5196-5202.

97 S. Wagner, J. Schnorr, A. Ludwig, V. Stangl, M. Ebert, B. Hamm and M. Taupitz, Int. J. Nanomed., 2013, 767-779.

98 D. G. You, G. Saravanakumar, S. Son, H. S. Han, R. Heo, K. Kim, I. C. Kwon, J. Y. Lee and J. H. Park, Carbohydr. Polym., 2014, 101, 1225-1233.

99 Z. M. Dong, S. M. Chapman, A. A. Brown, P. S. Frenette, R. O. Hynes and D. D. Wagner, J. Clin. Invest., 1998, 102, 145-152.

100 K. Wenzel, F. X. Felix, S. Kleber, R. Brachold, T. Menke, S. Schattke, K. L. Schulte, C. Glaser, K. Rohde, G. Baumann and A. Speer, Hum. Mol. Genet., 1994, 3, 1935-1937.

101 P. C. Burger and D. D. Wagner, Blood, 2002, 101, 2661-2666.

102 J. G. Park and G.-T. Oh, BMB Rep., 2011, 44, 497-505.

103 A. M. Morawski, G. A. Lanza and S. A. Wickline, Curr. Opin. Biotechnol., 2005, 16, 89-92.

104 F. Chaubet, I. Bertholon, J. M. Serfaty, R. Bazeli, H. Alsaid, M. Jandrot-Perrus, C. Zahir, P. Even, L. Bachelet, Z. Touat, E. Lancelot, C. Corot, E. Canet-Soulas and D. Letourneur, Contrast Media Mol. Imaging, 2007, 2, 178-188.

105 A. Hasan, G. D. Souza, B. M. Calude, C. Frederic, S. Abdulrazzaq, D.-M. Catherine, C. Linda, Z. Charaf, L. Eric, R. Olivier, C. Claire, P. Douek, A. Briguet, L. Didier and C. S. Emmanuelle, Invest. Radiol., 2009, 44, 151-158.

106 L. Chaabane, N. Pellet, M. C. Bourdillon, C. D. Mansard, A. Sulaiman, G. Hadour, F. Thivolet-Béjui, P. Roy, A. Briguet, P. Douek and E. C. Soulas, MAGMA, 2004, 17, 188-195.

107 E. A. Waters and T. J. Meade, Magnetic Resonance Angiography: Principles and Applications, Springer, New York, 2012, pp. 199-210.

108 S. Laurent, L. Vander Elst, Y. Fu and R. N. Muller, Bioconjugate Chem., 2004, 15, 99-103.

109 S. Boutry, C. Burtea, S. Laurent, G. Toubeau, L. Vander Elst and R. N. Muller, Magn. Reson. Med., 2005, 53, 800-807.

110 F. Hyafil, E. Vucic, J. C. Cornily, R. Sharma, V. Amirbekian, F. Blackwell, E. Lancelot, C. Corot, V. Fuster, Z. S. Galis,
L. J. Feldman and Z. A. Fayad, Eur. Heart J., 2010, 32, 1561-1571.

111 M. R. Makowski, S. C. Forbes, U. Blume, A. Warley, C. H. P. Jansen, A. Schuster, A. J. Wiethoff and R. M. Botnar, Atherosclerosis, 2012, 222, 43-49.

112 M. E. Andia, P. Saha, J. Jenkins, B. Modarai, A. J. Wiethoff, A. Phinikaridou, S. P. Grover, A. S. Patel, T. Schaeffter, A. Smith and R. M. Botnar, Arterioscler., Thromb., Vasc. Biol., 2014, 34, 1193-1198.

113 G. S. Loving and P. Caravan, Angew. Chem., Int. Ed., 2014, 53, 1140-1143.

114 M. Sirol, V. Fuster, J. J. Badimon, J. T. Fallon, P. R. Moreno, J.-F. Toussaint and Z. A. Fayad, Circulation, 2005, 112, 1594-1600.

115 M. Sirol, J. G. S. Aguinaldo, P. B. Graham, R. Weisskoff, R. Lauffer, G. Mizsei, I. Chereshnev, J. T. Fallon, E. Reis, V. Fuster, J.-F. Toussaint and Z. A. Fayad, Atherosclerosis, 2005, 182, 79-85.

116 H. Okamura, L. J. Pisani, A. R. Dalal, F. Emrich, B. A. Dake, M. Arakawa, D. C. Onthank, R. R. Cesati, S. P. Robinson, M. Milanesi, G. Kotek, H. Smit, A. J. Connolly, H. Adachi, M. V. McConnell and M. P. Fischbein, Circ. Cardiovasc. Imaging, 2014, 7, 690-696.

117 M. R. Makowski, A. J. Wiethoff, U. Blume, F. Cuello, A. Warley, C. H. P. Jansen, E. Nagel, R. Razavi, D. C. Onthank, R. R. Cesati, M. S. Marber, T. Schaeffter, A. Smith, S. P. Robinson and R. M. Botnar, Nat. Med., 2011, 17, 383-388.

118 D. Li, A. R. Patel, A. L. Klibanov, C. M. Kramer, M. Ruiz, B. Y. Kang, J. L. Mehta, G. A. Beller, D. K. Glover and C. H. Meyer, Circ. Cardiovasc. Imaging, 2010, 3, 464-472.

119 B. den Adel, L. M. van der Graaf, I. Que, G. J. Strijkers, C. W. Löwik, R. E. Poelmann and L. van der Weerd, Contrast Media Mol. Imaging, 2013, 8, 63-71.

120 C. Burtea, S. Ballet, S. Laurent, O. Rousseaux, A. Dencausse, W. Gonzalez, M. Port, C. Corot, L. Vander Elst and R. N. Muller, Arterioscler., Thromb., Vasc. Biol., 2012, 32, e36-e38.

121 X. Wu, N. Balu, W. Li, Y. Chen, X. Shi, C. M. Kummitha, X. Yu, C. Yuan and Z. R. Lu, Am. J. Nucl. Med. Mol. Imaging, 2013, 3, 446-455.

122 C. Burtea, S. Laurent, O. Murariu, D. Rattat, G. Toubeau, A. Verbruggen, D. Vansthertem, L. Vander Elst and R. N. Muller, Cardiovasc. Res., 2008, 78, 148-157.

123 A. Dellinger, J. Olson, K. Link, S. Vance, M. G. Sandros, J. Yang, Z. Zhou and C. L. Kepley, J. Cardiovasc. Magn. Reson., 2013, 15, 7.

124 Z. Zhou, R. P. Lenk, A. Dellinger, S. R. Wilson, R. Sadler and C. L. Kepley, Bioconjugate Chem., 2010, 21, 1656-1661.

125 L. Wang, X. Zhu, X. Tang, C. Wu, Z. Zhou, C. Sun, S.-L. Deng, H. Ai and J. Gao, Chem. Commun., 2015, 51, 4390-4393.

126 J. Querol, W. Chen, R. Weissleder and A. Bogdanov, Org. Lett., 2005, 7, 1719-1722.

127 R. Golestani, J. J. Jung and M. M. Sadeghi, J. Clin. Med., 2016, 5, DOI: 10.3390/jcm5060057.

128 E. Lancelot, V. Amirbekian, I. Brigger, J. S. Raynaud, S. Ballet, C. David, O. Rousseaux, S. Le Greneur, M. Port, H. R. Lijnen, P. Bruneval, J. B. Michel, T. Ouimet, 
B. Roques, A. Hyafil, E. Vucic, J. C. S. Aguinaldo, C. Corot and Z. A. Fayad, Arterioscler., Thromb., Vasc. Biol., 2008, 28, 425-432.

129 M. Nahrendorf, F. A. Jaffer, K. A. Kelly, D. E. Sosnovik, E. Aikawa, P. Libby and R. Weissleder, Circulation, 2006, 114, 1504-1511.

130 A. Tsourkas, V. R. Shinde-Patil, K. A. Kelly, P. Patel, A. Wolley, J. R. Allport and R. Weissleder, Bioconjugate Chem., 2005, 16, 576-581.

131 M. Michalska, L. Machtoub, H. D. Manthey, E. Bauer, V. Herold, G. Krohne, G. Lykowsky, M. Hildenbrand, T. Kampf, P. Jakob, A. Zernecke and W. R. Bauer, Arterioscler., Thromb., Vasc. Biol., 2012, 32, 2350-2357.

132 G. A. F. van Tilborg, E. Vucic, G. J. Strijkers, D. P. Cormode, V. Mani, T. Skajaa, C. P. M. Reutelingsperger, Z. A. Fayad, W. J. M. Mulder and K. Nicolay, Bioconjugate Chem., 2010, 21, 1794-1803.
133 S. Boutry, S. Laurent, L. V. Elst and R. N. Muller, Contrast Media Mol. Imaging, 2006, 1, 15-22.

134 K. A. Radermacher, N. Beghein, S. Boutry, S. Laurent, L. Vander Elst, R. N. Muller, B. F. Jordan and B. Gallez, Invest. Radiol., 2009, 44, 398-404.

135 M. H. El-Dakdouki, K. El-Boubbou, M. Kamat, R. Huang, G. S. Abela, M. Kiupel, D. C. Zhu and X. Huang, Pharm. Res., 2013, 31, 1426-1437.

136 P. M. Winter, A. M. Neubauer, S. D. Caruthers, T. D. Harris, J. D. Robertson, T. A. Williams, A. H. Schmieder, G. Hu, J. S. Allen, E. K. Lacy, H. Zhang, S. A. Wickline and G. M. Lanza, Arterioscler., Thromb., Vasc. Biol., 2006, 26, 2103-2109.

137 P. M. Winter, A. M. Morawski, S. D. Caruthers, R. W. Fuhrhop, H. Zhang, T. A. Williams, J. S. Allen, E. K. Lacy, J. D. Robertson, G. M. Lanza and S. A. Wickline, Circulation, 2003, 108, 2270-2274. 